Supplement of Atmos. Chem. Phys., 15, 6337-6350, 2015

http://www.atmos-chem-phys.net/15/6337/2015/

doi:10.5194/acp-15-6337-2015-supplement

(C) Author(s) 2015. CC Attribution 3.0 License.

(c) (i)

Atmospheric

Chemistry

and Physics

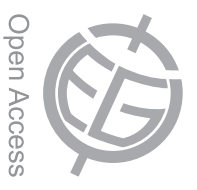

Supplement of

\title{
The role of organic condensation on ultrafine particle growth during nucleation events
}

D. Patoulias et al.

Correspondence to: S. N. Pandis (spyros@chemeng.upatras.gr)

The copyright of individual parts of the supplement might differ from the CC-BY 3.0 licence. 


\section{Supplementary material}

TABLE S1. Major compounds for each lumped VOC within SAPRC99 (Tsimpidi et al., 2010).

\begin{tabular}{|c|c|c|c|}
\hline Species & Major Components & Type of source & $\begin{array}{l}\text { V-SOA } \\
\text { precursors }\end{array}$ \\
\hline ALK1 & Ethane, Methyl Formate & Anthropogenic & No \\
\hline ALK2 & Propane, Cyclobutane, Ethyl Formate, Methyl Acetate & Anthropogenic & No \\
\hline ALK3 & $\begin{array}{l}\text { n-Butane, Ethanol, Isobutane, Dimethyl, Butane, } \\
\text { Dimethyl Pentane }\end{array}$ & Anthropogenic & No \\
\hline ALK4 & $\begin{array}{l}\text { n-Pentane, n-Hexane, Branched C5-C6, Alkanes, } \\
\text { Cyclopetane, Trimethyl Butane, Trimethyl Pentane, } \\
\text { Isopropyl Alcohol, n-Propyl Alcohol }\end{array}$ & Anthropogenic & Yes \\
\hline ALK5 & $\begin{array}{l}\text { C7-C22 n-Alkanes, C6-C16 Cycloalkanes, } \\
\text { Branched/Unspeciated C8-C18 Alkanes }\end{array}$ & Anthropogenic & Yes \\
\hline OLE1 & Propene, C4-C15 Terminal Alkenes & Anthropogenic & Yes \\
\hline OLE2 & $\begin{array}{l}\text { Isobutene, C4-C15 Internal Alkenes, C6-C15 Cyclic } \\
\text { or di-olefins, Styrenes }\end{array}$ & Anthropogenic & Yes \\
\hline ARO1 & $\begin{array}{l}\text { Toluene, Benzene, Ethyl Benzene, C9-C13 } \\
\text { Monosubstituted Benzenes }\end{array}$ & Anthropogenic & Yes \\
\hline $\mathrm{ARO} 2$ & $\begin{array}{l}\text { Xylenes, Ethyl Toluenes, Dimethyl and Trimethyl } \\
\text { Benzenes, Ethylbenzenes, Naphthalene, C8-C13 Di-, } \\
\text { Tri-, Tetra-,Penta-, Hexa-substituted Benzenes, } \\
\text { Unspeciated C10-C12 Aromatics }\end{array}$ & Anthropogenic & Yes \\
\hline TERP & $\begin{array}{l}\alpha \text {-pinene, } \beta \text {-pinene, Limonene, Carene, Sabinene, } \\
\text { other monoterpenes }\end{array}$ & Biogenic & Yes \\
\hline ISOP & Isoprene & Biogenic & Yes \\
\hline SESQ & Sesquiterpenes & Biogenic & Yes \\
\hline
\end{tabular}




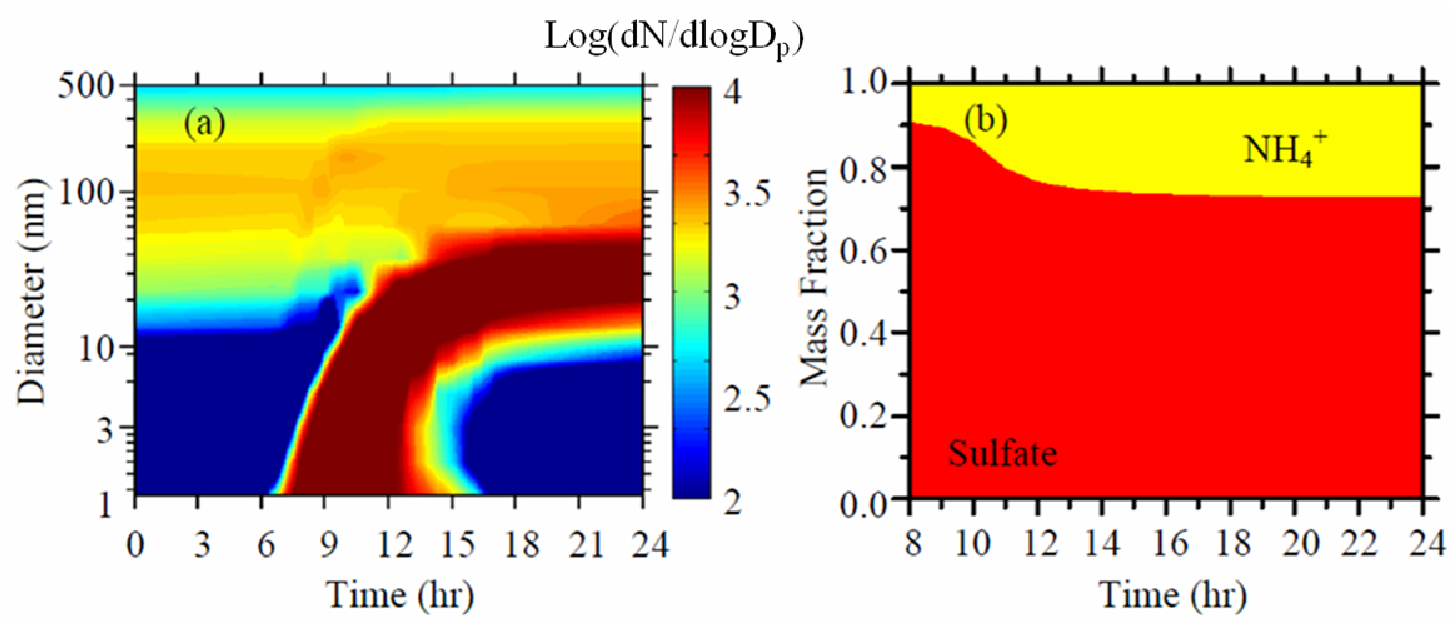

FIGURE S1: (a) Predicted aerosol dry size distribution during a typical spring day with a nucleation event at Finokalia without condensation of organics. Particle number concentration is plotted against time of day (x-axis) and particle diameter (y-axis). (b) Predicted composition of new particles. 


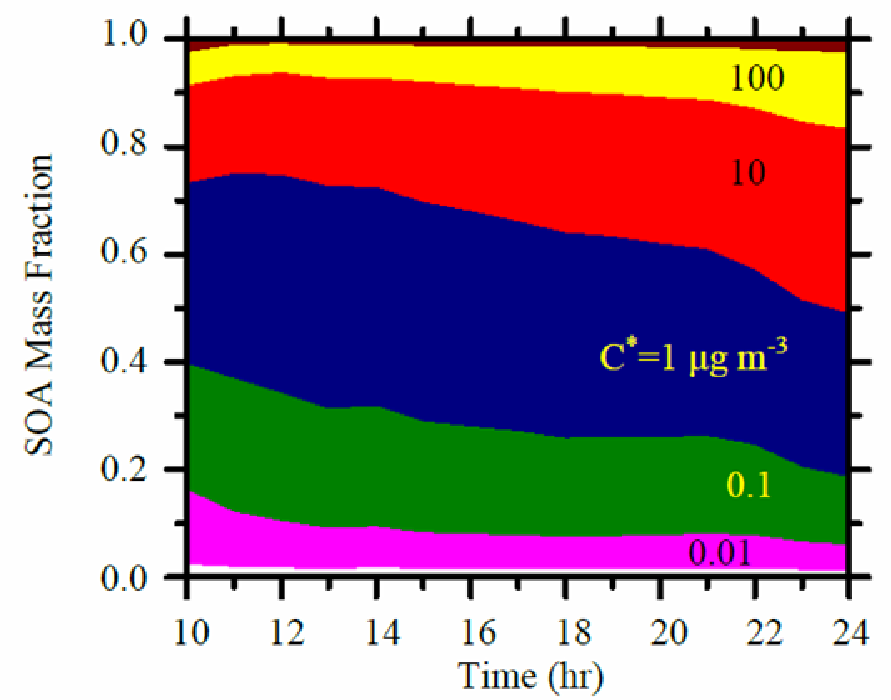

FIGURE S2: Predicted composition of organic aerosol in the new particles for different effective saturation concentrations with $\sigma=0.025 \mathrm{~N} \mathrm{~m}^{-1}$ at Hyytiala. 


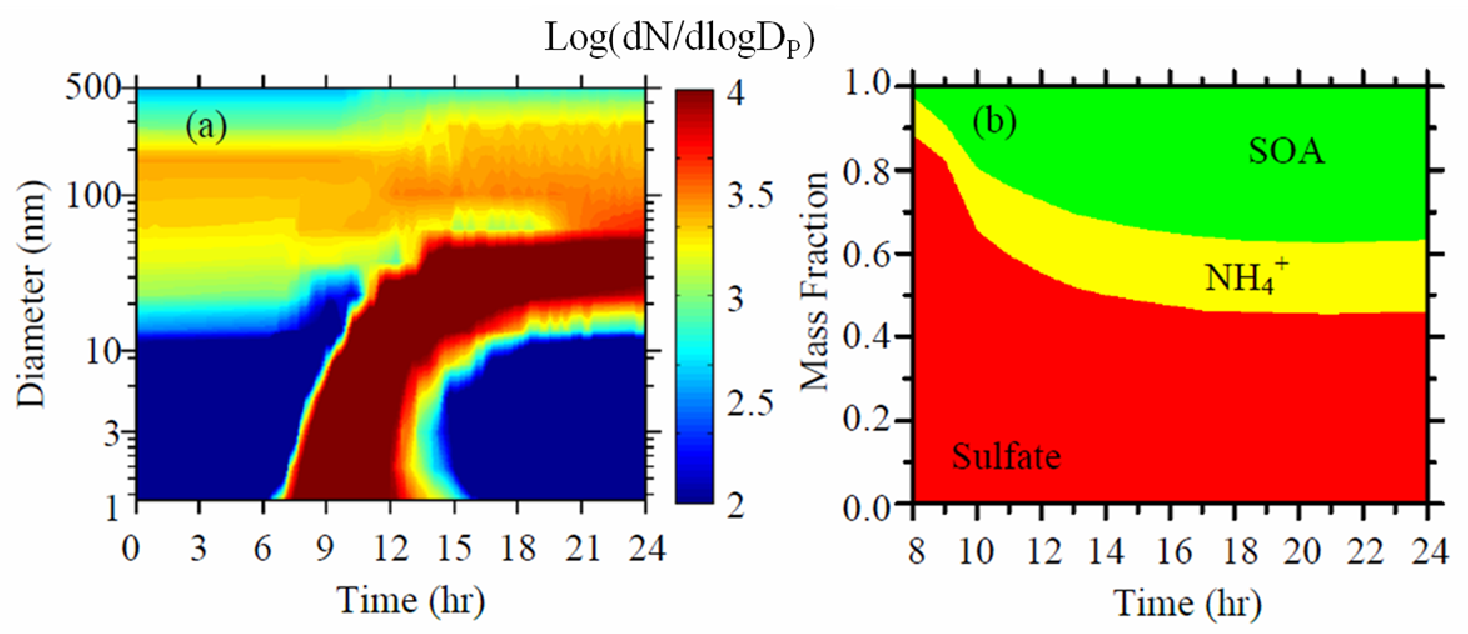

FIGURE S3: Simulation with surface tension of $0.025 \mathrm{~N} \mathrm{~m}^{-1}$ at Finokalia: (a) predicted particle size distribution and (b) the composition of nucleated particles. 


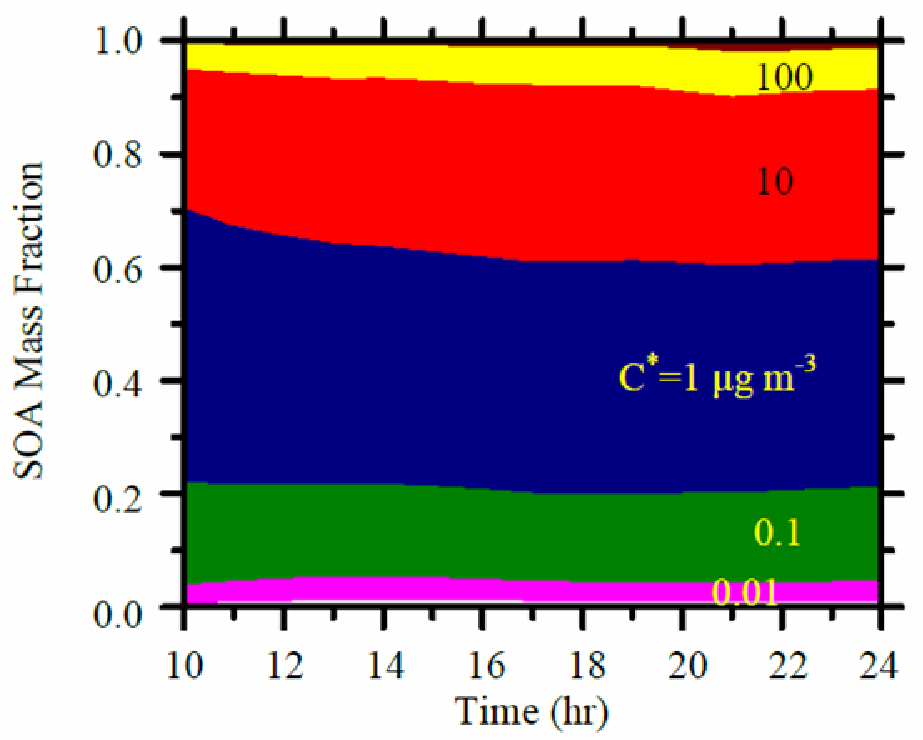

FIGURE S4: Predicted composition of organic aerosol in the new particles for different effective saturation concentrations with $\sigma=0.025 \mathrm{~N} \mathrm{~m}^{-1}$ at Finokalia. 


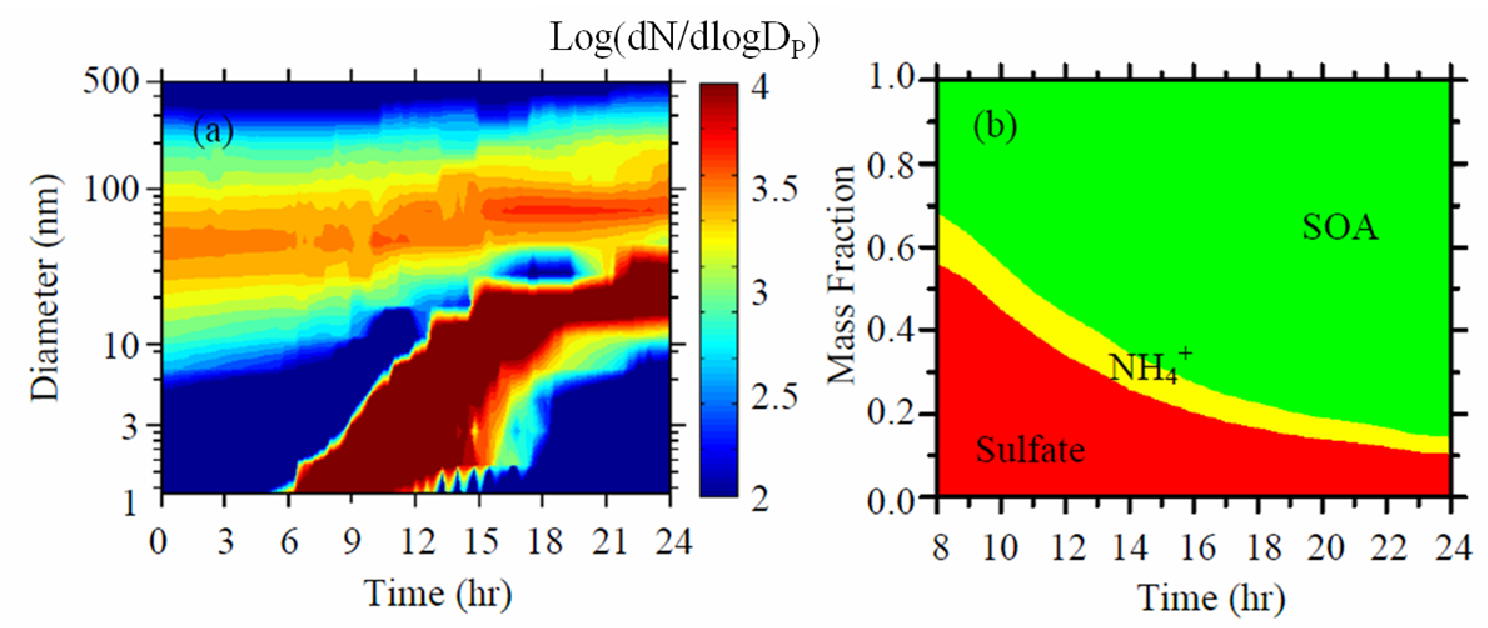

FIGURE S5: Simulation with condensation of organics neglecting the Kelvin effect and without the chemical aging of bSOA precursors at Hyytiala: (a) predicted aerosol dry size distribution and (b) composition of nucleated particles. 


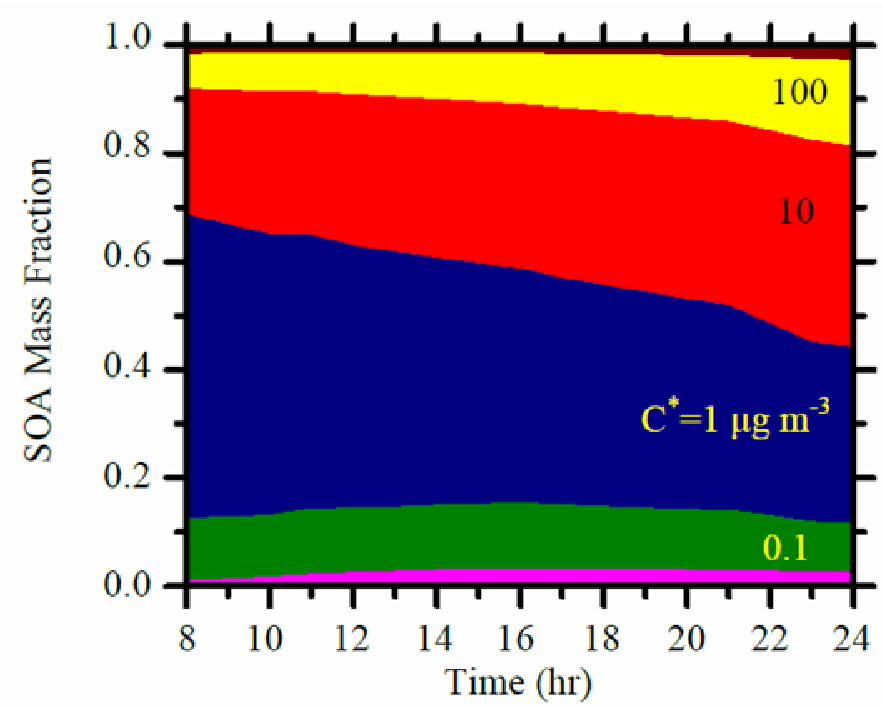

FIGURE S6: Predicted composition of organic aerosol in the new particles for different effective saturation concentrations with zero surface energy and without the chemical aging of bSOA precursors at Hyytiala. 


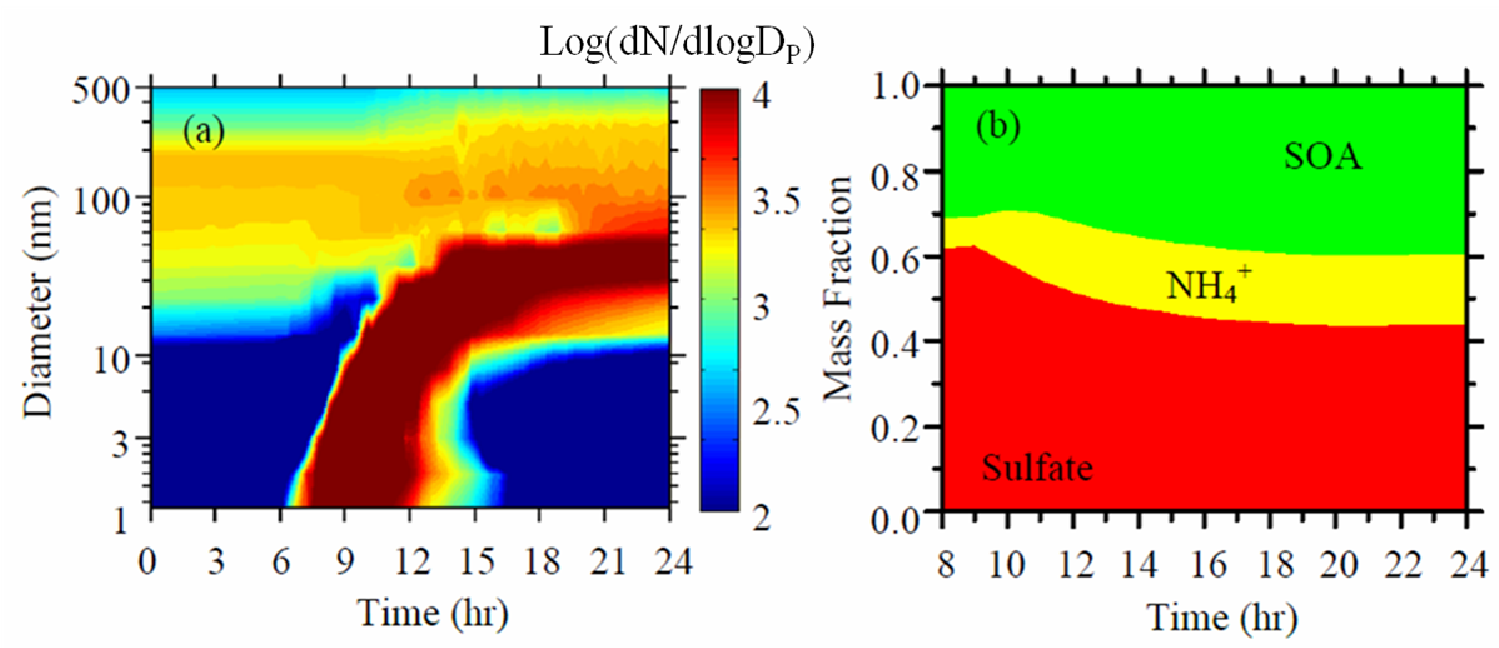

FIGURE S7: Simulation with condensation of organics neglecting the Kelvin effect and without the chemical aging of bSOA precursors at Finokalia as function of local time: (a) predicted particles size distribution and (b) the composition of nucleated particles. 


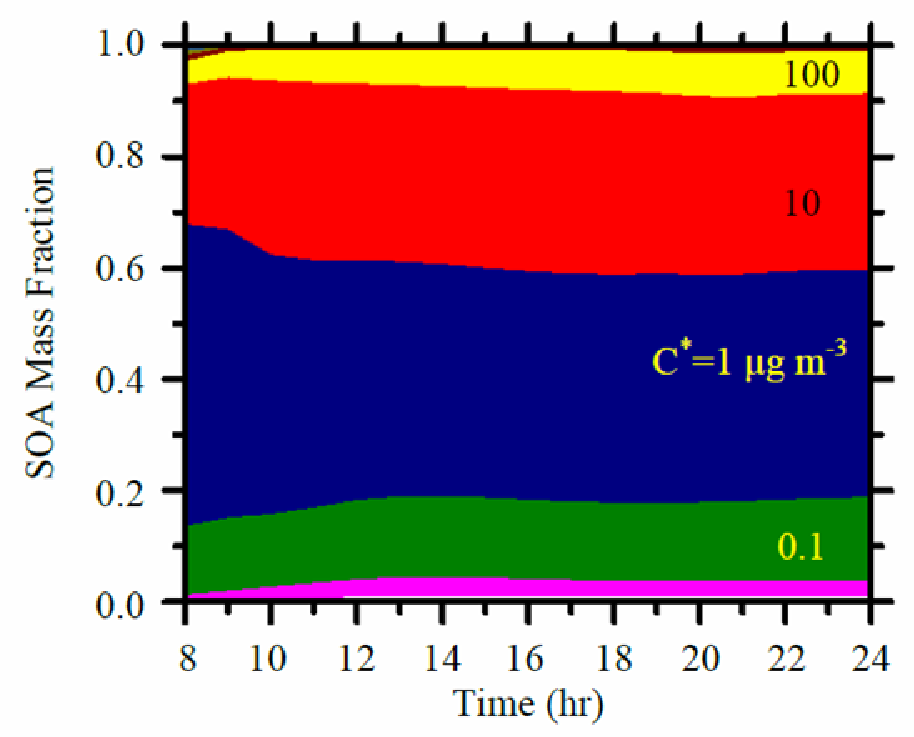

FIGURE S8: Predicted composition of organic aerosol in the new particles for different effective saturation concentrations with zero surface energy and without the chemical aging of bSOA precursors at Finokalia. 

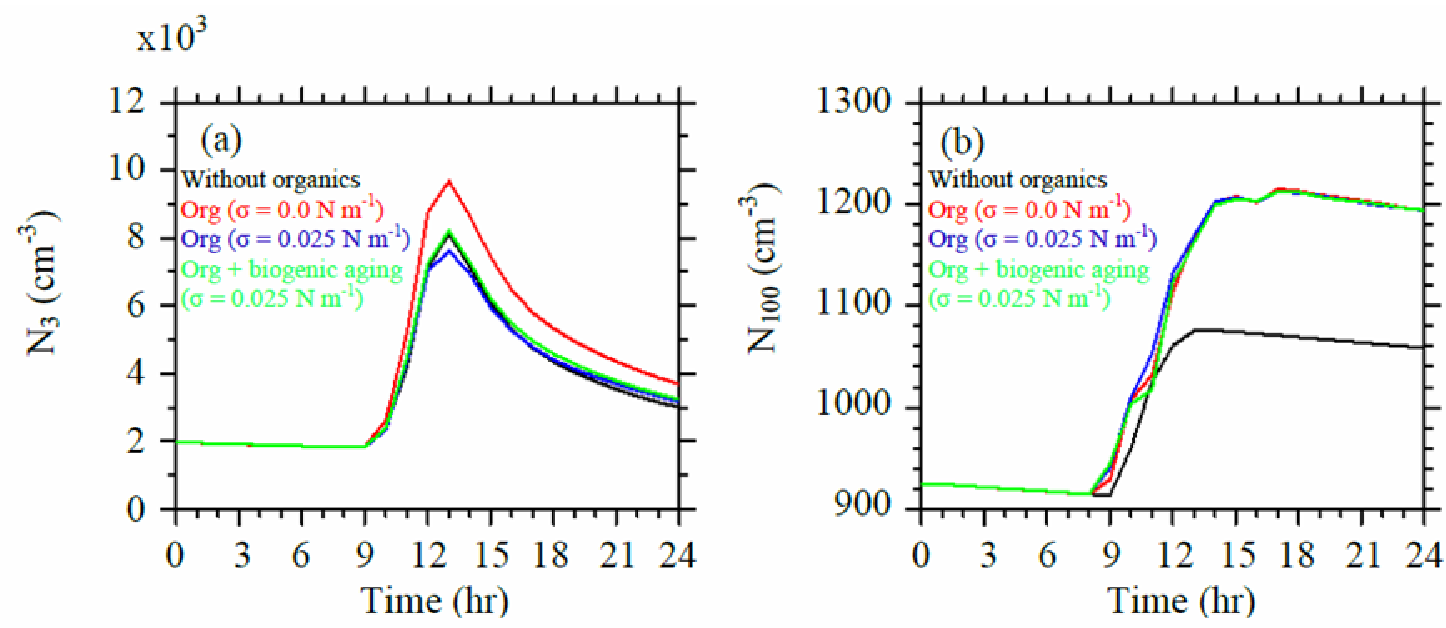

FIGURE S9: Predicted concentrations of (a) $\mathrm{N}_{3}$ and (b) $\mathrm{N}_{100}$ at Finokalia for the four simulated cases. Black line represents no condensation of organics, red is with condensation of organics with $\sigma=0.0 \mathrm{~N} \mathrm{~m}^{-1}$, blue is with condensation of organics with $\sigma=0.025 \mathrm{~N} \mathrm{~m}^{-1}$ and green is condensation of organics with aging reactions of bSOA precursors and $\sigma=0.025 \mathrm{~N} \mathrm{~m}^{-1}$. 